\title{
Detección y expresión de los receptores X retinoicos (RXR) en la mucosa yeyunal de crías de alpacas (Vicugna pacos)
}

\section{Detection and expression of retinoic $X$ receptors $(R X R)$ in the jejunal mucosa of baby alpaca (Vicugna pacos)}

\author{
Alessandra Bocanegra A. ${ }^{1}$, Alberto Manchego S. ${ }^{1,3}$, Miguel Rojas M. ${ }^{1}$, Gustavo Mur- \\ ga A. ${ }^{1}$, Nieves Sandoval C. ${ }^{2}$
}

\section{RESUMEN}

\begin{abstract}
El presente estudio determinó la presencia de los genes de las isoformas de los receptores $\mathrm{X}$ retinoicos (RXR) en el genoma de alpacas adultas y su expresión en la mucosa yeyunal de las crías de alpaca. Se utilizaron muestras de leucocitos sanguíneos de cinco alpacas adultas para detectar los genes de las isoformas RXRbeta y RXRgamma por PCR utilizando cebadores específicos, y para determinar la expresión de las isoformas de los genes RXR se utilizaron 35 muestras de yeyuno de crías de alpacas (1-50 días), a las cuales se les realizó la prueba de RT-PCR tiempo real. Los resultados indican que las alpacas tienen codificadas las isoformas de RXRbeta y RXRgamma en su genoma y que tienen distintos niveles de expresión en la mucosa yeyunal de las crías. Se detectó una alta expresión de RXRgamma y RXRbeta. Estos resultados indican que los receptores RXRgamma y RXRbeta se están expresando en la mucosa del yeyuno de crías de alpacas.
\end{abstract}

Palabras clave: receptores X retinoicos, RXR, PCR, RT PCR tiempo real, mucosa yeyunal, crías, alpacas

\footnotetext{
${ }^{1}$ Laboratorio de Microbiología y Parasitología Veterinaria, Facultad de Medicina Veterinaria, Universidad Nacional Mayor de San Marcos, Lima, Perú

${ }^{2}$ Laboratorio de Histología, Embriología y Patología Animal, Facultad de Medicina Veterinaria, Universidad Nacional Mayor de San Marcos, Lima, Perú

${ }^{3}$ E-mail: amanchegos@unmsm.edu.pe; https://orcid.org/0000-0002-8199-0418
}

Recibido: 23 de septiembre de 2019

Aceptado para publicación: 2 de abril de 2021

Publicado: 23 de junio de 2021

CLos autores. Este artículo es publicado por la Rev Inv Vet Perú de la Facultad de Medicina Veterinaria, Universidad Nacional Mayor de San Marcos. Este es un artículo de acceso abierto, distribuido bajo los términos de la licencia Creative Commons Atribución 4.0 Internacional (CC BY 4.0) [https:// creativecommons.org/licenses/by/4.0/deed.es] que permite el uso, distribución y reproducción en cualquier medio, siempre que la obra original sea debidamente citada de su fuente original 
The present study determined the presence of retinoic $\mathrm{X}$ receptor isoforms (RXR) genes in the genome of adult alpacas and their expression in the jejunal mucosa of alpaca offspring. Blood leukocyte samples from five adult alpacas were used to detect the genes of the RXRbeta and RXRgamma isoforms by PCR using specific primers, and to determine the expression of the RXR gene isoforms, 35 jejunum samples from young alpacas were used (1-50 days old), to which the real-time RT-PCR test was performed. The results indicate that the alpacas have encoded the RXRbeta and RXRgamma isoforms in their genome and that they have different levels of expression in the jejunal mucosa of baby alpacas. High expression of RXRgamma and RXRbeta was detected. These results indicate that the RXRgamma and RXRbeta receptors are being expressed in the mucosa of the jejunum of baby alpacas.

Key words: X retinoic receptors, RXR, PCR, real time RT PCR, jejunal mucosa, pups, alpaca

\section{INTRODUCCIÓN}

El sistema inmune de los camélidos sudamericanos (CSA) se encuentra poco estudiado, sobre todo respecto a la respuesta inmune en la mucosa intestinal. El sistema inmune mucosal posee ciertas funciones principales como proteger las membranas mucosales contra la colonización e invasión de agentes potencialmente peligrosos, prevenir el paso de antígenos sin degradar y evitar el desarrollo de respuestas inmunes potencialmente perjudiciales (Holmgre y Czerkinsky, 2005).

La vitamina $A$ es fundamental para la respuesta inmune de mucosas a nivel intestinal, debido a la dependencia de las células linfoides al estímulo de sus metabolitos. Entre estos, el más importante es el ácido retinoico, el cual induce a los linfocitos $\mathrm{B}$ intraepiteliales a producir inmunoglobulina $\mathrm{A}$ (IgA). La tolerancia inmune intestinal es inducida en parte por el ácido retinoico, considerándose una señal reguladora clave (Wang et al., 2010). Además, permite la estimulación de las células dendríticas para la generación de células T reg (Sun et al., 2007). Por esta razón, se ha asociado la presencia de ácido retinoico con el tropismo de células $\mathrm{T}$ y $\mathrm{B}$ en su migración hacia el intestino delgado, concepto denominado alojamiento («homing») linfoide (Kim, 2008).

El ácido retinoico, en sus formas isoméricas all-trans y 9-cis, se producen a partir de células del intestino tales como las células dendríticas que proporcionan una señal ambiental específica en el intestino y en los tejidos linfoides asociados (Iwata y Yokota, 2011). Los receptores «homing» intestinales de las células linfoides en las alpacas son inducidos en su expresión en las células de una manera dependiente de antígeno y de ácido retinoico (Hermoza et al., 2018). El ácido retinoico es también una señal necesaria e importante que induce a las células B presentes intraepitelialmente o en los tejidos linfoides asociados a la mucosa intestinal a producir Ig A (Mora y von Andrian, 2009). Las células $\mathrm{T}$ y $\mathrm{B}$ de alojamiento (homing) en el intestino son las células que juegan un papel esencial en la protección del tracto digestivo frente a patógenos (McGhee y Fujihashi, 2012). El ácido retinoico también participa en la producción de fagocitos maduros en la medula ósea, produciendo 
monocitos CD11b+CD11c-Ly6C bajo/intermedio con fenotipo supresor y células dendríticas $\mathrm{CD} 11 \mathrm{c}^{+}$no supresoras que podrían contribuir a una mayor proliferación celular (VanGundy et al., 2014). Además el ácido retinoico producido localmente en la mucosa intestinal induce a la proliferación de células $\mathrm{T}$ reguladoras (activadas por el activador transcripcional FoxP3) que son importantes para el mantenimiento de la tolerancia inmune en el intestino; cumpliendo roles antagónicos que permiten la homeostasis de la función inmune en esta mucosa (Kim, 2008)

El reconocimiento del ácido retinoico (RA) es a través de los receptores retinoicos (RAR) y receptores $\mathrm{X}$ retinoicos (RXR), que se expresan en las células linfoides asociadas a la mucosa y otras células epiteliales. Los receptores de ácido retinoico se pueden dividir en tres tipos de isoformas, RARs (alfa, beta y gama) y RXRs (alfa, beta y gamma), cuyas distribuciones son tejidos específicos (Niederreither y Dolle, 2008). El RA influencia la diferenciación, crecimiento celular y función de estos receptores (Dawson et al., 2008).

Se ha identificado gran parte del genoma de la alpaca, pero falta confirmar, entre otros, la presencia y expresión de los receptores $\mathrm{X}$ retinoicos (RXR) en la mucosa intestinal y determinar las isoformas que se expresan en el tejido yeyunal. Por esta razón, el objetivo del presente trabajo fue determinar la expresión de las isoformas de los receptores $\mathrm{X}$ retinoicos (RXR) en la mucosa yeyunal de las crías de alpacas.

\section{Materiales y MéTodos}

\section{Animales y Muestras}

Se emplearon cinco alpacas adultas, entre machos y hembras, criadas en las instalaciones de la Facultad de Medicina Veterinaria de la Universidad Nacional Mayor de
San Marcos, Lima, Perú, a las cuales se les extrajo $5 \mathrm{ml}$ de sangre en tubos con anticoagulante EDTA en enero de 2018, que sirvieron para la obtención de ADN genómico.

Paralelamente se utilizaron 35 yeyunos de crías de alpaca, entre recién nacidas y hasta cerca de 50 días de edad. Los yeyunos fueron obtenidos durante un muestreo en un rebaño de la comunidad de Silly en Maranganí, Cusco, Perú en 2015. En esa fecha las crías fueron sacrificadas según el protocolo de Autorización N. ${ }^{\circ}$ 2009-001 del Comité de Ética y Bienestar Animal de la Facultad de Medicina veterinaria de la Universidad Nacional Mayor de San Marcos. Las muestras de yeyuno $(2 \mathrm{~cm})$ fueron conservadas en nitrógeno líquido a $-196{ }^{\circ} \mathrm{C}$ hasta su uso en el presente trabajo.

\section{Detección de Genes RXR}

Las cinco muestras de sangre fueron centrifugadas a $2000 \mathrm{rpm}$ por $5 \mathrm{~min}$. Se extrajo la capa blanca intermedia (capa leucocítica) utilizando una pipeta Pasteur y se colocó en tubos Falcon. De cada tubo se tomó $200 \mu$ l para determinar la presencia de los genes RXRbeta y RXRgamma mediante PCR en el genoma de las alpacas muestreadas. Para la extracción y purificación del ADN genómico de cada alpaca fue empleado el PureLink ${ }^{\mathrm{TM}}$ Genomic DNA Mini Kits (Invitrogen, USA) siguiendo los procedimientos del fabricante. El ADN purificado fue almacenado a $-20{ }^{\circ} \mathrm{C}$ hasta su uso en la PCR convencional.

\section{Cebadores}

Se usó el software Primer-Blast para la obtención de los cebadores de cada uno de los genes utilizando las secuencias establecidas en el Genbank, siendo los códigos de los genes los siguientes: RXRb XM_015237344.1 y RXRg XM_006209028.2 (Cuadro 1). 


\section{Extracción de ADN y ARN Total}

De las muestras de yeyuno se realizaron cortes de $150 \mathrm{mg}$ de peso. Las secciones fueron lavadas con suero fisiológico al $0.9 \%$ y fueron machacadas. El machacado se reconstituyó con $500 \mu 1$ de agua libre de nucleasas. Se obtuvieron dos alícuotas de $250 \mu 1$ por cada muestra y fueron conservadas en nitrógeno líquido a $-196{ }^{\circ} \mathrm{C}$ hasta su uso para la extracción de los RNA mensajeros totales y ADN genómico.

Para la obtención de los ARN totales y el ADN genómico de cada muestra se utilizó el reactivo Trizol® (Invitrogen, USA) según las indicaciones del fabricante. En tubos Eppendorrf de $2 \mathrm{ml}$ se colocó $250 \mu 1$ del machacado y $1 \mathrm{ml}$ de trizol, se agitó y se incubó a temperatura ambiente por $10 \mathrm{~min}$ y se centrifugó a $10000 \mathrm{rpm}$ por 10 minutos a ${ }^{\circ} \mathrm{C}$. Del centrifugado se obtuvo una fase acuosa (sobrenadante), una fase intermedia y una fase orgánica o fenólica. Se recolectó el sobrenadante en un nuevo tubo Eppendorf de $1.5 \mathrm{ml}$, que contiene el RNA total de la muestra al cual se le agregó $250 \mu 1$ de cloroformo e isopropanol, se agitó $30 \mathrm{~s}$, se incubó $1 \mathrm{~h} 4{ }^{\circ} \mathrm{C}$; y luego se centrifugó a $10000 \mathrm{rpm}$ durante $15 \min$ a $4{ }^{\circ} \mathrm{C}$. Se eliminó el sobrenadante y el precipitado fue lavado dos veces con $500 \mu \mathrm{l}$ de etanol al $75 \%$, vórtex por $15 \mathrm{~s}$ y centrifugación a $8800 \mathrm{rpm}$ durante 5 min a $4{ }^{\circ} \mathrm{C}$, eliminando el sobrenadante por inversión. Luego se secó el precipitado a temperatura ambiente. Por último, el precipitado se resuspendió en $30 \mu 1$ de agua libre de nucleasas y almacenó a $-20^{\circ} \mathrm{C}$.

Cuadro 1. Cebadores para la Reacción en Cadena de la Polimerasa con Transcriptasa I(RTPCR) tiempo real y para el secuenciamiento

\begin{tabular}{|c|c|c|c|c|}
\hline & Gen/ cebador & Secuencia & $\begin{array}{l}\text { Tamaño del } \\
\text { cebador }(\mathrm{pb})\end{array}$ & $\begin{array}{l}\text { Tamaño del } \\
\text { producto } \\
(\mathrm{pb})\end{array}$ \\
\hline \multicolumn{5}{|l|}{ RT-PCR } \\
\hline & $\begin{array}{l}\text { RXRb pacos } \\
\text { rtimesFor }\end{array}$ & TATGTGCAATCTGCGGGGAC & 20 & 115 \\
\hline & $\begin{array}{l}\text { RXRb pacos } \\
\text { rtimesRev }\end{array}$ & CGGCATGAGTAGGTCAGGTC & 20 & \\
\hline & $\begin{array}{l}\text { RXRg pacos } \\
\text { rtimesFor }\end{array}$ & CTGGGCTCTCCGTATCGAGT & 20 & 127 \\
\hline & $\begin{array}{l}\mathrm{RXRg} \text { pacos } \\
\text { rtimesRev }\end{array}$ & $\begin{array}{c}\text { TGCTGACACTGTTGACCACA } \\
\text { T }\end{array}$ & 21 & \\
\hline \multicolumn{5}{|l|}{ Secuenciamiento } \\
\hline & $\begin{array}{l}\text { RXRb pacos } \\
\text { SecFor }\end{array}$ & CCCCCTGAAGATGTGAAGCC & 20 & 554 \\
\hline & $\begin{array}{l}\text { RXRb pacos } \\
\text { SecRev }\end{array}$ & ATCCTCTTCGCCCACTCAAC & 20 & \\
\hline & $\begin{array}{l}\text { RXRg pacos } \\
\text { SecFor }\end{array}$ & $\begin{array}{c}\text { CCCATCGGCAGCCTTATCTA } \\
\text { C }\end{array}$ & 21 & 720 \\
\hline & $\begin{array}{l}\text { RXRg pacos } \\
\text { SecRev }\end{array}$ & TTGGTGACAGGGTCATTCGT & 20 & \\
\hline
\end{tabular}


De la fase intermedia se obtuvo el ADN total de la muestra. Esta fase se colocó en tubo Eppendorf de $1.5 \mathrm{ml}$ y se le agregó $1 \mathrm{ml}$ de cloroformo e isopropanol y incubó durante $2 \mathrm{~h}$ a $4{ }^{\circ} \mathrm{C}$, luego se centrifugó a 10000 rpm por $15 \mathrm{~min}$. Se eliminó el sobrenadante y el precipitado fue lavado dos veces con etanol al $75 \%$, tal y como se indica para la obtención de los RNA totales. El ADN total también se diluyó en $30 \mu 1$ de agua libre de nucleasas y se conservó a $-20^{\circ} \mathrm{C}$ hasta su uso.

El ARN total y el ADN total de las muestras de yeyuno y sanguíneas se cuantificaron usando el kit Quant-it ${ }^{\mathrm{TM}}$ (Invitrogen, USA) siguiendo las instrucciones del fabricante y usando el fluorómetro de Qubit ${ }^{\mathrm{TM}}$ (Invitrogen, USA). Luego, se procedió a realizar diluciones en agua libre de nucleasas para trabajar con $1 \mu \mathrm{g}$ en un volumen de $2 \mu \mathrm{l}$ por muestra.

\section{PCR}

El PCR fue utilizado para identificar los genes de las isoformas de receptores retinoicos (RXRs) en ADN de leucocitos sanguíneos. Se usaron los cebadores diseñados para este trabajo, utilizando el kit Gotaq PCR Core Systems (Promega) con una desnaturación inicial de $95^{\circ} \mathrm{C}$ por 2 min y 25-35 ciclos de desnaturación a $95{ }^{\circ} \mathrm{C}$ por $30 \mathrm{~s}$, alineamiento a $42-65^{\circ} \mathrm{C}$ por $30 \mathrm{~s}$ y extensión de $72{ }^{\circ} \mathrm{C}$ por $1 \mathrm{~min}$, una extensión final a $72{ }^{\circ} \mathrm{C}$ por 5 min y a $4{ }^{\circ} \mathrm{C}$ indefinido. Los productos obtenidos fueron revelados en geles de agarosa al $1.5 \%$ por electroforesis a $80 \mathrm{v}$ por $1 \mathrm{~h}$.

Para detectar el gen de RXRb se realizó un PCR anidado utilizando para la primera PCR los cebadores de secuenciamineto y para el segundo PCR el cebador RXRbeta pacos SecForward y RXRbeta pacos rtimesRev produciendo un producto de $466 \mathrm{pb}$.

\section{Síntesis de ADNc (Transcripción Reversa)}

El ARN total de cada muestra fue utilizado como base para la síntesis de ADNc empleando el kit SV Total RNA Isolation System» (Promega), según las instrucciones del fabricante. Los componentes tuvieron un último volumen de $20 \mu \mathrm{l}$ por reacción/muestra en sus concentraciones (2xRT Reaction $\operatorname{mix} 10 \mu \times \mathrm{n}$, RT enzyme mix $1 \mu 1 \times \mathrm{n}$, hexámeros al azar $1 \mu \mathrm{l} \times \mathrm{n}, \mathrm{H}_{2} \mathrm{O} 6 \mu \mathrm{l} \times \mathrm{n}$, donde $n$ significa el número de muestras a trabajar.

\section{PCR a Tiempo Real}

El ADNc fue analizado mediante PCR en tiempo real cuantitativo en triplicado usando el Termociclador tiempo real modelo CFX96 ${ }^{\text {TM }}$ Touch Real-time PCR Bio-Rad. La cantidad inicial (SQ) de la muestra de ADNc inicial fue calculada de curvas estándar cebador-específico usando el software de análisis de información iCycler. El nivel de expresión de cada gen fue normalizado al nivel de expresión de GAPDH usando un método de curva estándar. Se utilizó $2 \mu 1$ de RNA de muestra completando a $25 \mu 1$ de volumen final con el buffer mix del kit SYBR GreenER qPCR Super Mix y el protocolo de 2 min a $50{ }^{\circ} \mathrm{C}$, por 10 min a $95^{\circ} \mathrm{C}$ (activación del ADN polimerasa), por $15 \mathrm{~s}$ a $95^{\circ} \mathrm{C}$ se dieron 45 ciclos seguidos, y finalmente por $60 \mathrm{~s} \mathrm{a} 60^{\circ} \mathrm{C}$. Los resultados se visualizaron a través del software CFX Manager de Bio-Rad, obteniéndose los valores del ciclo umbral $(\mathrm{Ct})$ y las temperaturas de disociación o melting (Tm) de cada uno de los productos obtenidos en la PCR.

\section{Análisis de la Información}

El análisis filogenético de las secuencias de los genes de los animales fue analizado mediante los métodos Fast Minimum 


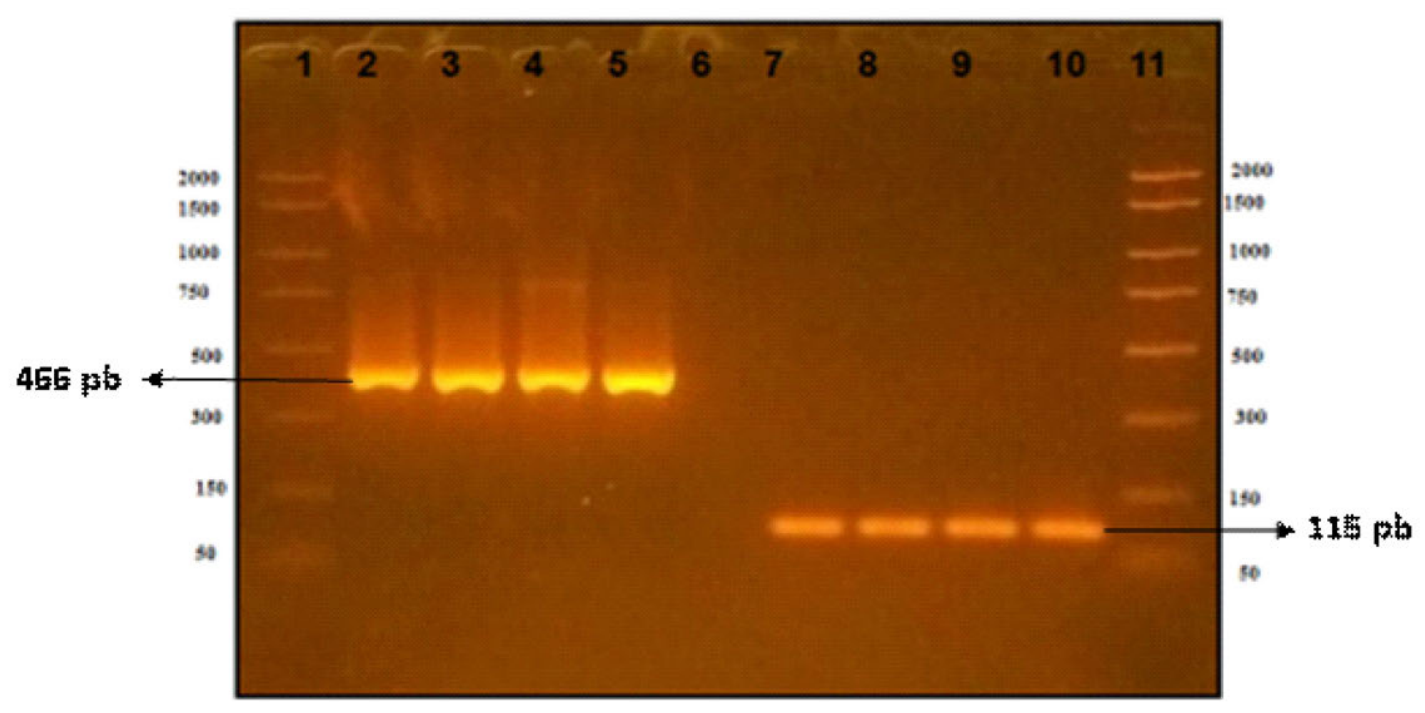

Figura 1. Electroforesis en gel de agarosa al $1.5 \%$ de los productos del PCR utilizando cebadores para el gen RXRbeta teniendo como molde el ADN genómico de los leucocitos sanguíneos (del carril 2 al 5) y los productos del RT-PCR del mismo gen utilizando como molde el ARNm obtenido de mucosa intestinal de alpaca (del carril 7 al 10)

Evolution, para determinar la cercanía evolutiva de los genes en estudio, y el método Neighbor joining para determinar la identidad y cercanía filogenética entre los individuos analizados.

\section{Resultados}

\section{Detección del Gen RXRbeta en Sangre}

Se determinó la presencia del gen RXRbeta en el DNA genómico de leucocitos de las alpacas, observándose un producto único de 466 pares de bases (pb) de la PCR anidada en el gel de agarosa utilizando los cebadores diseñados para el secuenciamiento del gen en la primera reacción de PCR y utilizando el cebador RXRbeta pacos SecForward y RXRbeta pacos rtimesRev en la segunda PCR produciendo un producto de $466 \mathrm{pb}$ (Figura 1).
Se realizó un gel de agarosa del producto del RT-PCR tiempo real y se obtuvo un solo producto con $115 \mathrm{pb}$, determinando la especificidad de los cebadores diseñados para determinar al gen RXRbeta de alpacas.

\section{Expresión del Gen RXRbeta en Yeyuno}

Se determinó la expresión del gen RXRbeta en la mucosa yeyunal de las crías de alpaca por RT PCR tiempo real en donde se observan curvas de amplificación (Ct) con valores que van de 13 a 16 (Figura 2), indicando la presencia de distintas concentraciones de ARN mensajeros del gen RXRbeta y determinando la expresión de este gen en el yeyuno.

La especificidad de cada producto del RT-PCR tiempo real de muestras utilizadas de yeyuno se determinó con la curva de disociación $(\mathrm{Tm})$. Los resultados indican que las 
muestran tienen un solo producto (un solo pico de disociación) y posee un $\mathrm{Tm}$ de $85^{\circ} \mathrm{C} \pm$ $1{ }^{\circ} \mathrm{C}$, determinando que el RT-PCR tiempo real es altamente específico para el producto esperado del gen RXRbeta (Figura 3).

\section{Secuenciamiento y Análisis Bioinfor- mático del Gen RxRbeta}

El secuenciamiento del producto de la PCR utilizando los cebadores para el gen RXRbeta determinó una secuencia de 364 $\mathrm{pb}$ en una alpaca que tuvo la mayor cantidad de producto en el RT-PCR anidado. El análisis de alineamiento para identificar la identidad del producto con el banco de datos de la NCBI (GenBank) indicó una alta identidad con el RXRbeta de Camelos ferus de $99.72 \%$ (357/358) y una identidad de $98 \%(358 / 364)$ con la variante X1 de alpaca (Vicugna pacos) (GenBankXM_015237344.1).

La secuencia del gen RXRbeta obtenida del ADN genómico de leucocitos sanguíneos fue la siguiente:

5'_TCCGTAAGGACCTGACCTACTCATGCCGGGACAACAAAGACTGCACGGTGGACAAGCGCCAGCGGAACCGCTGTCAGTACTGCCGCTATCAAAAGTGCCTGGCCACTGGCATGAAGAGGGAGGCGGTACAGGAGGAGCGTCAGCGGGGGAAGGACAAAGATGGGGATGGGGAGGGGGCTGGGGGAGCCCCTGAGGAGATGCCGGTGGACAGGATCCTGGAGGCAGAGCTTGCTGTGGAGCAGAAGAGTGACCAGGGCGTTGAGGGTCCTGGGGGAACCGGGGGTGGCGGCAGCAGCCCAAATGACCCAGTGACTAACATCTGTCAGGCAGCTGACAAGCAGCTATTCACGCTTGTTGACT 3'

El análisis filogenético se realizó utilizando secuencias nucleotídicas de los receptores RXR depositadas en el Genbank, que fueron seleccionadas después de haber realizado el blast de la secuencia del gen RXRbeta. Se pudo determinar que la secuencia obtenida es filogenéticamente más próxima a las secuencias de alpaca variante 1
(Vicugna pacos) con un porcentaje de identidad del $98.35 \%$ (Figura 4) y muestra un segundo nodo con los camélidos del viejo mundo (Camelus ferus, Camelus dromedarius y Camelus bactrianus) con un porcentaje de identidad de $99.72 \%$ (Figura 5). Fuera de estas especies se observó una relación filogenética cercana al gen de RXRbeta de los primates y animales placentarios, rinocerontes (Ceratotherium simum simum), mamíferos ungulados con dedos impares, carnívoros y murciélagos y más lejanos, las ballenas y delfines (95.81\% de identidad) (Figuras 4 y 5).

\section{Detección del Gen RXRgamma en Sangre}

Se determinó la presencia del gen RXRgamma en el DNA genómico del pool de leucocitos de las alpacas adultas en estudio observándose un producto único de 608 pares de bases (pb) de la PCR anidada en el gel de Agarosa (Figura 6).

\section{Expresión del Gen RXRgamma en Yeyuno}

Se determinó la expresión del gen RXRgamma en el yeyuno de las crías de alpaca por RT PCR tiempo real, donde se observan curvas de amplificación $(\mathrm{Ct})$ con valores que van entre 16 y 20 , indicando la presencia de distintas concentraciones de ARN mensajeros del gen RXRgamma en yeyuno de las crías de alpaca, determinando la expresión de este gen en el yeyuno (Figura 7). Los productos de RT-PCR tiempo real fue corrido en gel de agarosa mostrando una sola banda de 280 pb según lo esperado (Figura 6).

La especificidad de cada producto del RT-PCR tiempo real se determinó con la curva de disociación $(\mathrm{Tm})$. Los resultados indican que las muestran tienen un solo producto (un solo pico de disociación) y que están en rango de 83 a $88^{\circ} \mathrm{C}$ de $\mathrm{Tm}$, siendo la mayoría de $85^{\circ} \mathrm{C}$. Se muestra que el RT-PCR tiempo real es altamente específico para el producto esperado del gen RXRgamma (Figura 8). 


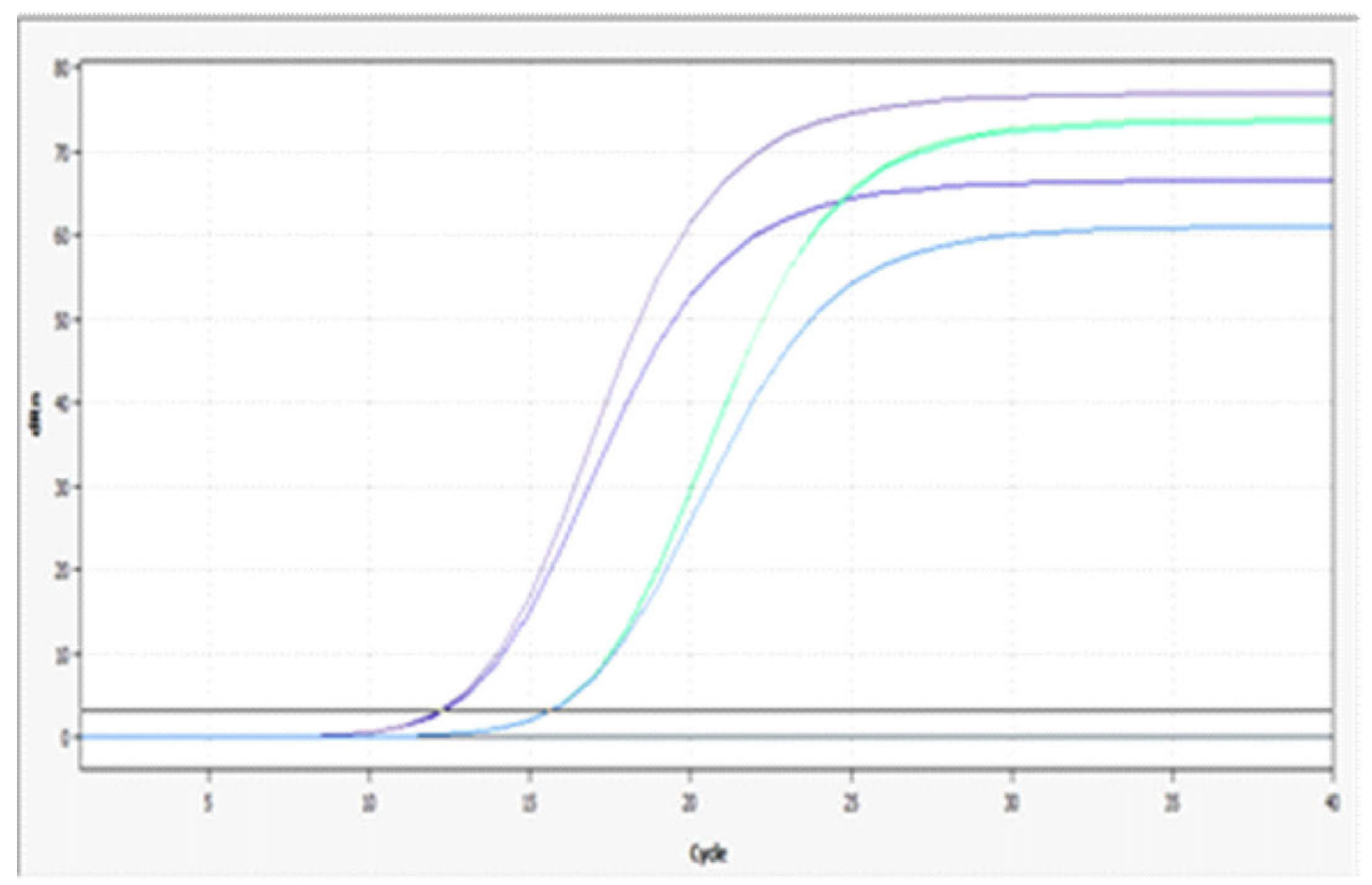

Figura 2. RT-PCR tiempo real de tres muestras y un control de yeyuno de crías de alpaca de distintas edades. Se observan curvas de amplificación $(\mathrm{Ct})$ para el gen RXRbeta con un rango de 13 a 16.
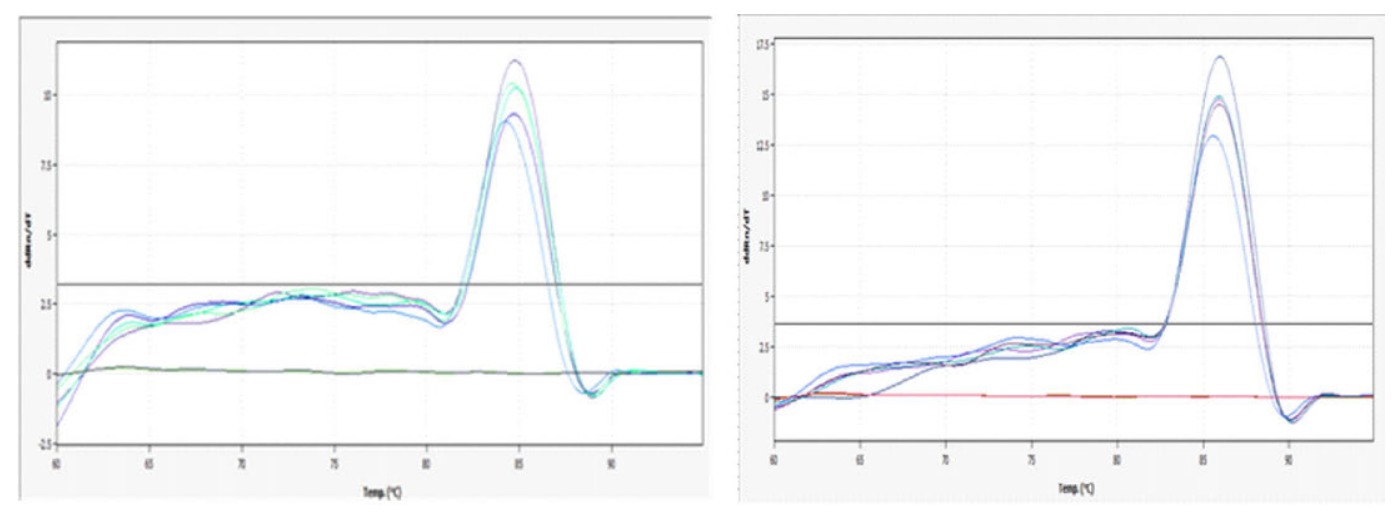

Figura 3. Derivada de la curva de disociación o Melting (Tm) de los productos del gen RXRbeta producidos en una reacción de PCR en tiempo real. Se muestra una Tm de $85{ }^{\circ} \mathrm{C} \pm 1{ }^{\circ} \mathrm{C}$ 


\section{Secuenciamiento y Análisis Bioinfor- mático del Gen RxRgamma}

El secuenciamiento del producto de la PCR utilizando los cebadores de RXRgamma determinó una secuencia de $534 \mathrm{pb}$ en una alpaca que tuvo la mayor cantidad de producto en el RT-PCR anidado, la cual muestra una identidad de 99\% (533/534) con la variante X1 del receptor gamma en alpacas (Vicugna pacos) (GenBank XM_006209028.2).

La secuencia fue:

5, TCAGGAGCACTGGCAGCCCCTCCAGGAATCAATTTGGTTGCCCCGCCCAGCTCTCAGCTAAATGTGGTCAACAGTGTCAGCATTTCAGAGGACATCAAGCCCTTATCAGGGCTTCCCGGCATCGGAAATATGAACTACCCGTCCACTAGCCCTGGCTCTCTGGTTAAACACATCTGTGCCATCTGCGGGGACAGATCCTCAGGGAAGCACTATGGTGTGTACAGTTGTGAAGGCTGCAAAGGGTTCTTCAAGAGAACCATAAGGAAAGACCTCATCTACACGTGCCGGGACAATAAAGACTGCCTCATTGACAAGCGCCAG-
CGTAACCGGTGCCAATACTGCCGCTATCAGAAGTGCCTTGTCATGGGCATGAAGAGGGAAGCTGTGCAAGAAGAGAGGCAGAGAAGCCGGGAGCGGGCAGAGAGTGAGGCGGAGTGTGCCAGCAGCGGCCATGAAGACATGCCTGTGGAGAGGATTCTAGAAGCTGAACTTGCCGTTGAACCAAAGACGGAATCCTATGGTGACATGAACATG-3'

El análisis filogenético de la secuencia del gen RXRgamma de la cría de alpaca mostró un nodo con RXRgamma variante X1 y X2, y un nodo más lejano con los camélidos del viejo mundo. La secuencia obtenida es filogenéticamente más próxima a las secuencias de alpaca variante 1 (Vicugna pacos) con un porcentaje de identidad del $99.8 \%$, y a la de los camélidos del antiguo mundo (Camelus ferus, Camelus dromedarius y Camelus bactrianus) con un porcentaje de identidad del $97.56 \%$. Fuera de estas especies se observó, además, una relación filogenética cercana al gen de RXRgamma variante 1 de primates, conejos, porcinos, equinos, ballenas y delfines (Figuras 9 y 10) con un rango de identidad de 93 a $94 \%$.

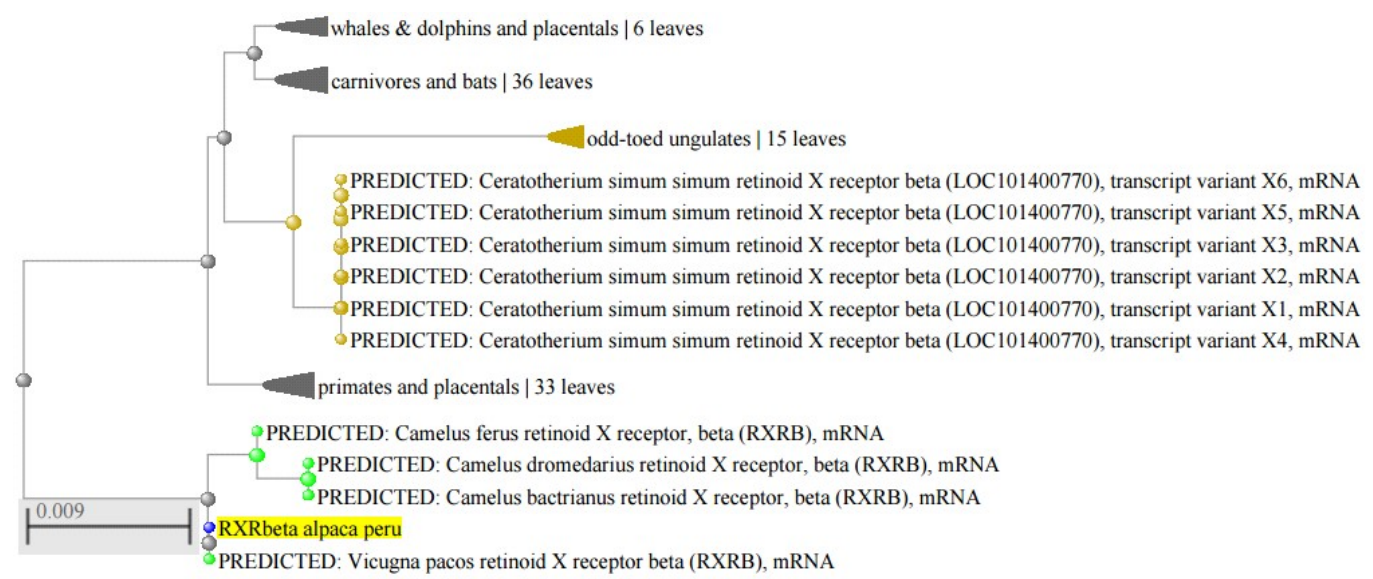

Figura 4. Dendograma del gen RXRbeta de crías de alpaca provenientes de Maranganí, CuscoPerú, con el método Fast Minimum Evolution. Max Seq Difference 0.1 


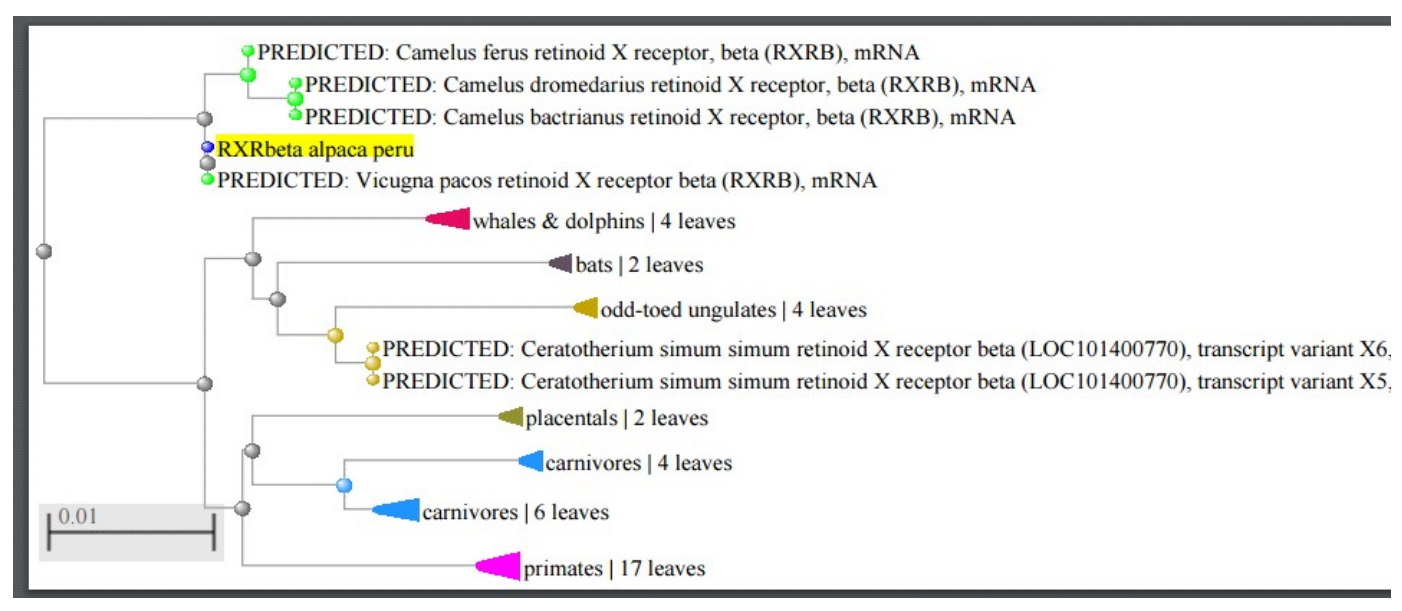

Figura 5. Dendograma del gen RXRbeta de crías de alpaca provenientes de Maranganí, CuscoPerú con el método Neighbor joining. Max Seq Difference 0.1

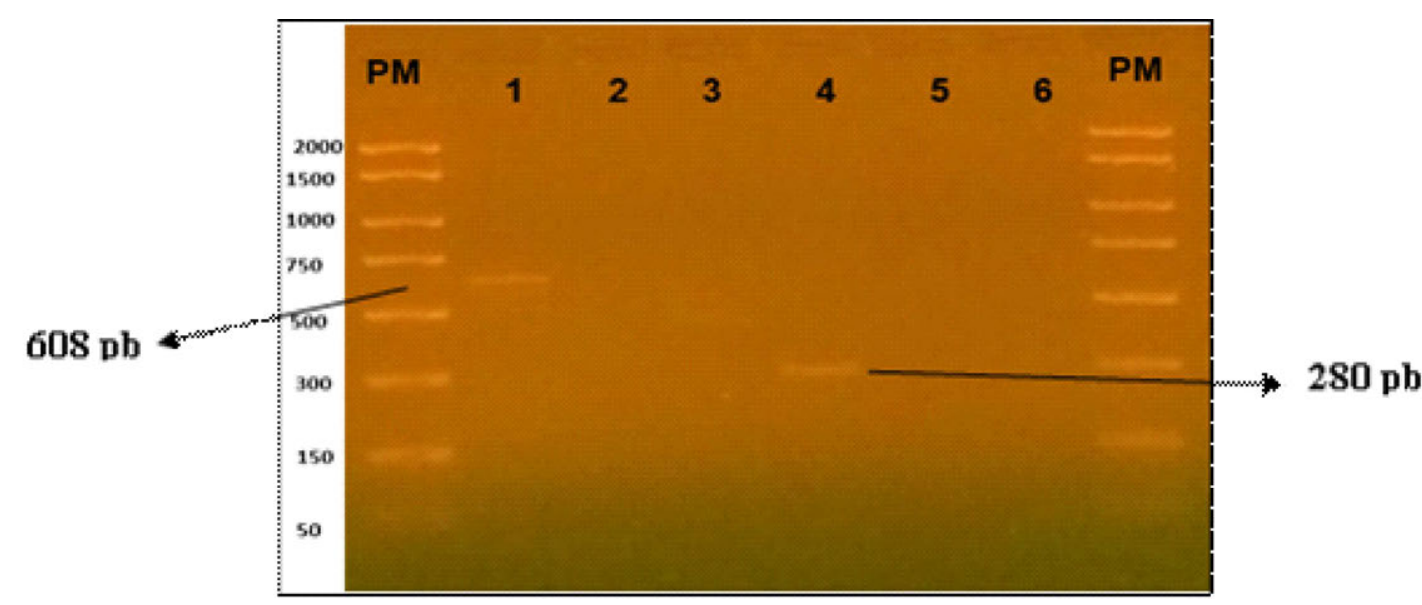

Figura 6. Gel de agarosa al 1.5\% mostrando los productos de PCR del gen RXRgamma. Cuenta con 604 pb usando DNA genómico como molde (Carril 1) y un producto del RT-PCR tiempo real del mismo gen de $280 \mathrm{pb}$ usando ARN total de yeyuno de cría de alpaca (Carril 4)

\section{Discusión}

Se determinó la presencia de los genes de los receptores $\mathrm{X}$ retinoicos (RXR) en el genoma de alpacas adultas y su expresión en la mucosa yeyunal de crías de alpacas
(Vicugna pacos). Se determinó la presencia del gen del receptor RXRbeta en los leucocitos sanguíneos de las alpacas adultas, utilizando los cebadores diseñados en base al gen putativo RXRbeta XM 015237344.1, lo cual confirmó la predicción informática de este gen en el genoma de la alpaca. 

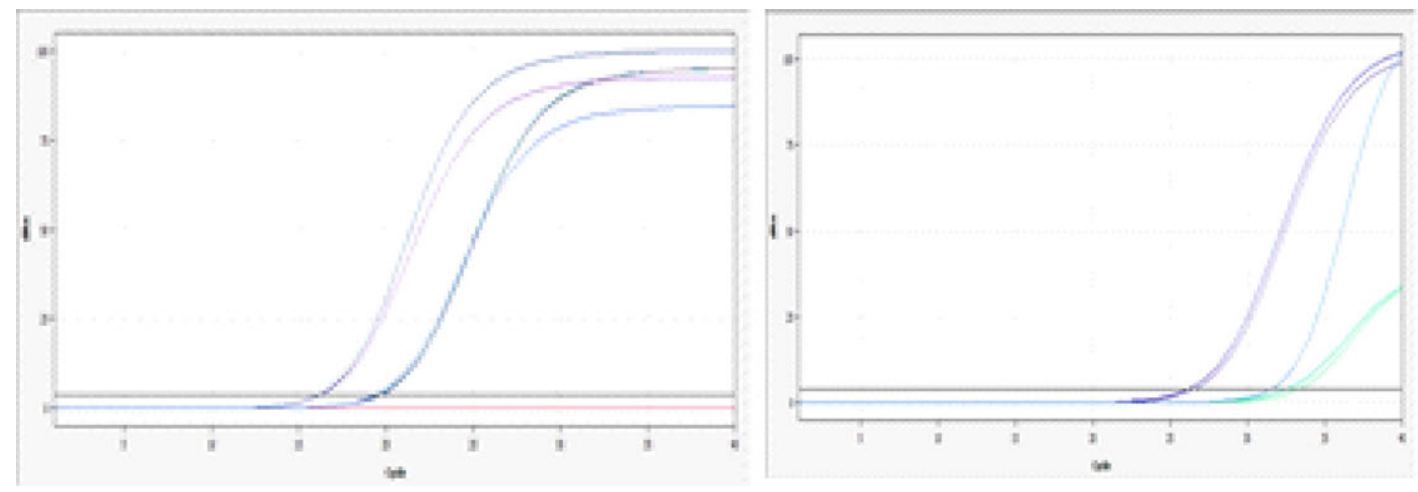

Figura 7. RT-PCR tiempo real de muestras de yeyuno de crías de alpaca (0-50 días de edad). Se observan curvas de amplificación $(\mathrm{Ct})$ para el gen RXRgamma con un amplio rango de 16 a 35

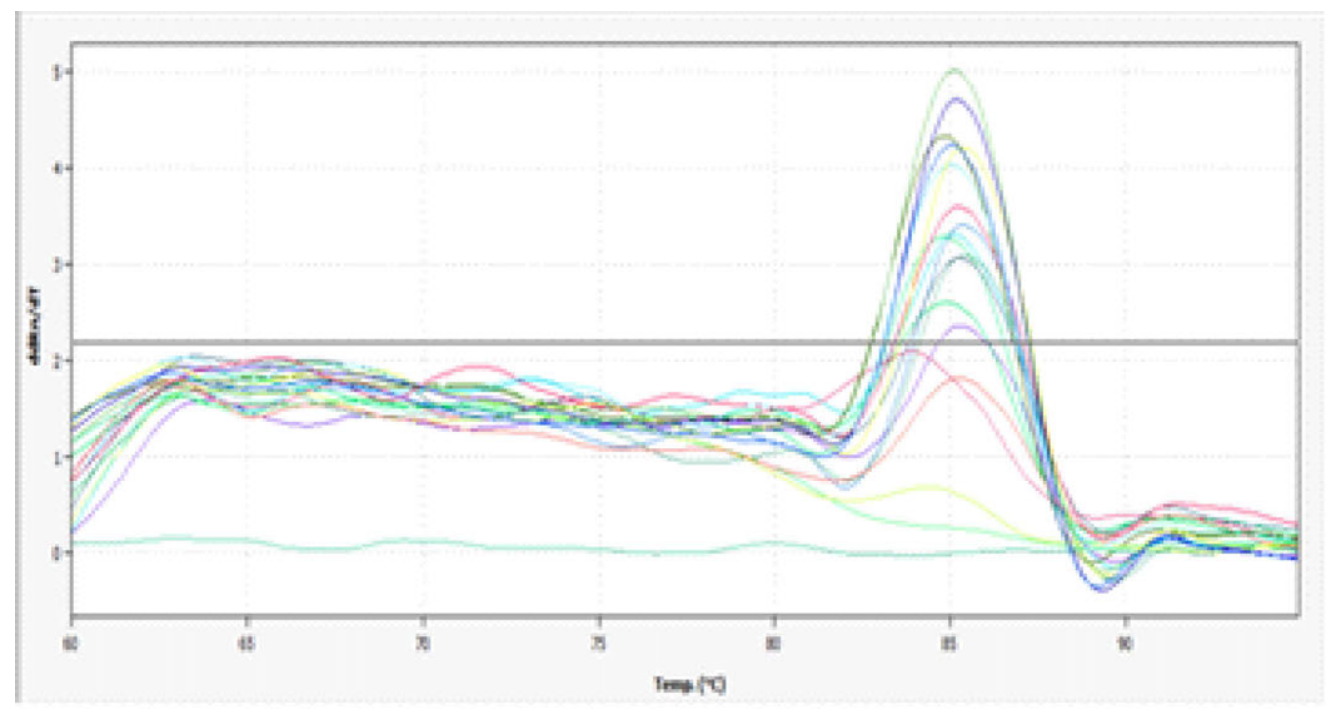

Figura 8. Curvas de disociación o temperatura de Melting $(\mathrm{Tm})$ realizados con el set de cebadores para el gen RXRgamma de la mucosa yeyunal de crías de alpaca. Los resultados tuvieron un rango de 83 a $88^{\circ} \mathrm{C}$

El alineamiento de la secuencia obtenida del fragmento del gen RXRbeta indica que tiene una identidad alta (99.72-99.44\%) de un fragmento de 358 nucleótidos con el gen RXRbeta de los camélidos del viejo mundo y de $98.35 \%$ con los camélidos sudamericanos, pero con un fragmento mayor de 362 nucleótidos, indicando que el receptor es altamente conservado en las especies de los camélidos. Esta alta conservación es debido a que cumplen funciones muy variadas en la fisiología de la especie como es el control del desarrollo embrionario, diferenciación celular, y en mantener la homeostasis metabólica 


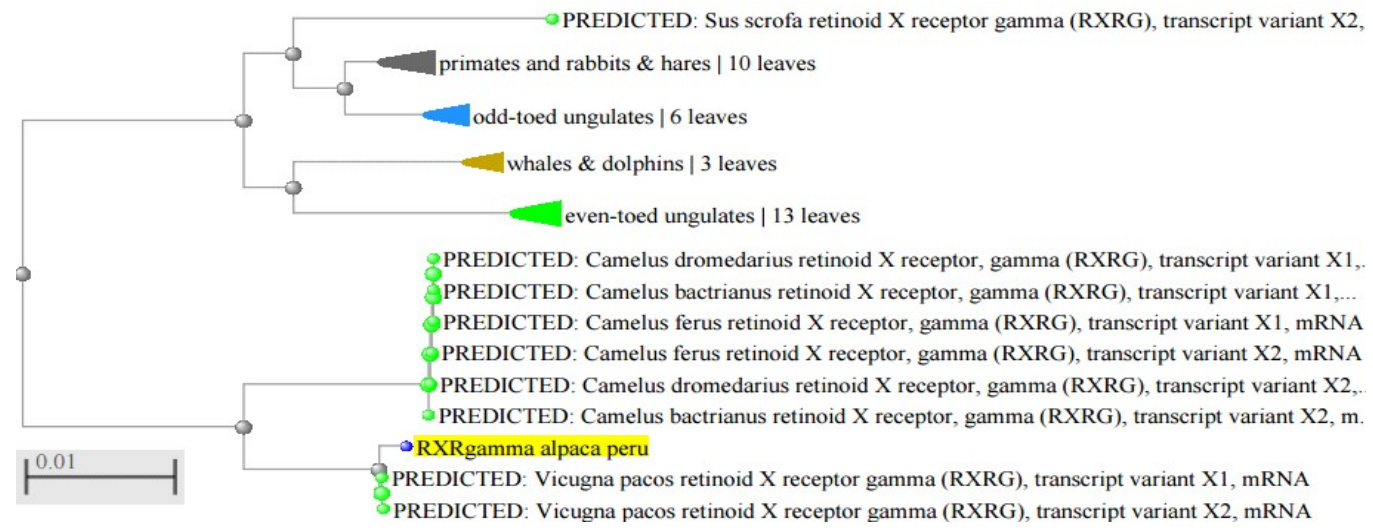

Figura 9. Dendograma del gen RXRgamma de crías de alpaca provenientes de Maranganí, Cusco-Perú, con el método Fast Minimum Evolution. Max Seq Difference 0.1

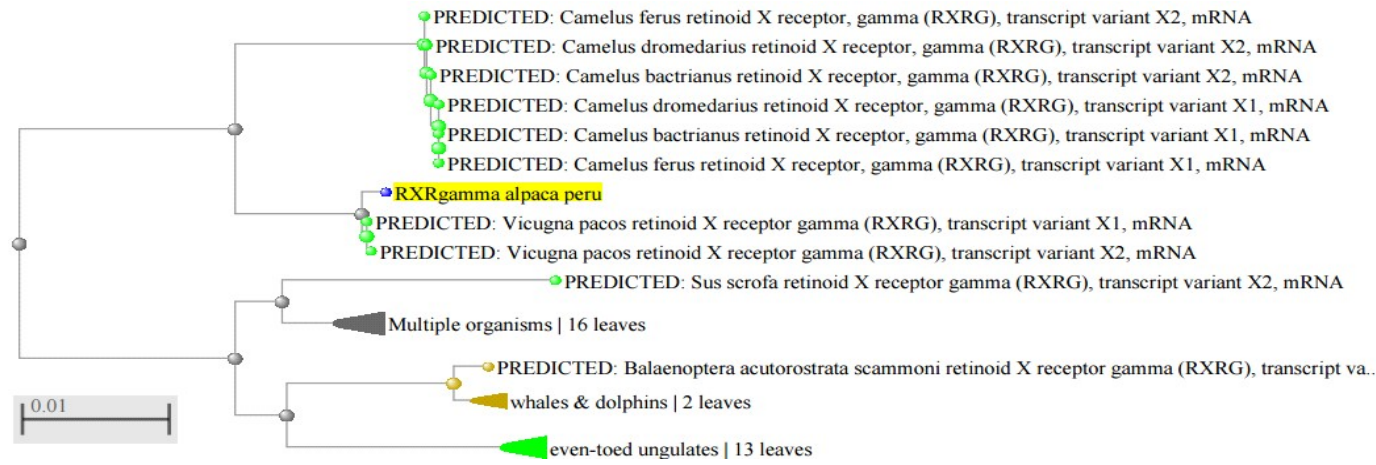

Figura 10. Dendogramas del gen RXRgamma de crías de alpaca provenientes de Maranganí, Cusco-Perú, con el método Neighbor joining. Max Seq Difference 0.1

(Gronemeyer et al., 2004; Sonoda et al., 2008). Los cebadores usados en este trabajo no diferencian las variantes de RXRbeta que se han determinado en las especies animales (Nagataavb et al., 1994; Keightley, 1998), teniendo alta identidad con las especies filogenéticamente más cercanas como los camélidos del viejo mundo (Wheeler, 1995).
El gen RXRbeta se expresó en el yeyuno de las crías de alpaca. La literatura en humanos indica que la localización de expresión de este gen es ubicua, con niveles más altos en el sistema nervioso central (Liu y Linney, 1993; Lefebvre et al., 2010). El gen RXRbeta muestra diferentes niveles de expresión en las muestras procesadas, posi- 
blemente debido a que sus niveles de expresión varían con el tipo de célula y el estado de diferenciación. Estudios en humanos revelan que los RXR son evidenciados por todo el organismo, tanto en el embrión como en el adulto (Lane y Bailey, 2005). Con base a esto, se puede considerar que los receptores RXR en la alpaca, junto a sus isoformas, pueden estar ubicados en diversos órganos, sobre todo en aquellos que cumplen las funciones fisiológicas por las cuales se destacan estos receptores.

El análisis filogenético utilizando el RXRbeta en estudio dio una cercanía filogenética con los camélidos del viejo mundo, similar a los estudios filogenéticos utilizando otros marcadores genéticos como las inmunoglobulinas (Nguyen, 2002) y ADN mitocondrial (Stanley et al., 1994). En este análisis podemos observar que el porcentaje de identidad que posee la alpaca con los camélidos del viejo mundo, especialmente con Camelus ferus (99\%). Los resultados del porcentaje de similitud podrían indicar que los camélidos del viejo mundo tienen mayor similitud con la secuencia obtenida; sin embargo, al evaluar la cantidad de pares de bases de cada especie mencionada se pude notar que a pesar de tener menor coincidencia la variante Vicugna pacos en sus pares de bases la cantidad final es mayor que en las pares de bases de los camélidos del viejo mundo. Por esa razón es que el porcentaje fue $1 \%$ menor al de los camélidos del viejo mundo, lo cual indica, además, que ambas especies tienen una secuencia muy similar en cuanto al gen RXRbeta.

En esta investigación también se pudo determinar la presencia del gen del receptor RXRgamma en los leucocitos sanguíneos de las alpacas. La ubicación del gen RXRgamma no se encuentra estudiada en los cromosomas del genoma de la alpaca, como es en el caso de los camélidos en general. No obstante, existen estudios sobre la localización del gen RXRgamma en humanos, el cual se encuentra ubicado en el cromosoma 1 (banda q22 q23) (Mangelsdorf et al., 1992). El gen RXRgamma posee dos variables entre sus genes en el caso de los ratones (Liu y Linney, 1993; Lefebvre et al., 2010). La primera es la variable RXR $\gamma 1$, se expresa en el músculo esquelético, bulbo olfatorio y glándula pituitaria, mientras que la segunda variable, RXR $\gamma 2$, se expresa tanto en el músculo cardíaco como en el músculo esquelético (Bookout et al., 2006). En los humanos, RXR $\gamma$ está predominantemente en la glándula pineal (Wu et al., 2009).

La variabilidad que se encuentra en las diversas isoformas del receptor RXR se debe a que cada gen puede dar lugar a diferentes variables por medio de empalmes alternativos y/o utilización de promotores alternativos (Asson-Batres y Rochette-Egly, 2014). Esto podría indicar que al existir una serie de variables para cada isoforma de RXR, los cebadores utilizados no podrían abarcar todas las variables existentes para cada isoforma. Sin embargo, los resultados evidenciaron la presencia de RXRbeta y RXRgamma, lo cual indica que, probablemente en el caso de la alpaca, la cantidad de variables que poseen las dos isoformas mencionadas no sea muy alta. Asimismo, en este trabajo se evidenció que el receptor RXRgamma tuvo una ligera mayor presencia que el receptor RXRbeta en las muestras procesadas, posiblemente debido a que el receptor RXRgamma tiene menor cantidad de variables que el receptor RXRbeta.

Se bien se pudo observar la presencia de distintas concentraciones de ARN mensajeros del gen RXRgamma en el yeyuno de las crías de alpaca, no se pudo realizar una cuantificación relativa de la expresión de los genes RXR por no contar con el calibrador adecuado ni el gen normalizador (housekeeping) para utilizar el método del $2^{-\Delta \Delta \mathrm{cT}}$ que es el empleado para esta cuantificación (Dheda et al., 2004).

La especificidad de los productos amplificados del gen RXRgamma fue comprobada por existir concordancia en los valores respectivos de temperatura de Melting (Tm). Estos valores tuvieron un rango de 83 a $88^{\circ} \mathrm{C}$ para el gen RXRgamma, indicando que los 
cebadores permiten la polimerización de más de una isoforma de RXRgamma. La expresión de los RXRbeta y RXRgamma en la mucosa intestinal concuerda con su participación en la regulación del sistema inmune de mucosas, principalmente en el establecimiento de las células linfoides en el intraepitelio intestinal en donde se sugiere que la activación de RXR mejora la expresión dependiente de RAR de CCR9 en las células $\mathrm{T}$ y su capacidad de retorno al intestino delgado (Takeuchi et al., 2010).

El alineamiento de la secuencia obtenida del fragmento del gen RXRgamma indica una alta identidad (99.8\%), teniendo un fragmento de 533 de un total de 534 nucleótidos con el gen RXRgamma en el caso de los camélidos sudamericanos, en especial con la variante X1 Vicugna pacos. Para el caso de la identidad en los camélidos del viejo mundo, esta fue de $97.56 \%$ con un fragmento menor de 329 nucleótidos (NCBI), indicando que el receptor tiene un alto grado de conservación en las especies de los camélidos. Esto indica que el contenido Guanina-Citosina (G-C), la secuencia de los genes y el tamaño de los amplicones es similar entre ambos (Dawson y Xia, 2014).

\section{Conclusiones}

- Se determinó la presencia de los genes RXRbet y RXRgamma en las alpacas del Perú.

- RXRbeta y RXRgamma se expresan en la mucosa yeyunal de crías de alpaca.

- RXRbeta y RXRgamma de las alpacas tienen alta homología con los camélidos del viejo mundo.

\section{Literatura Citada}

1. Asson-Batres MA, Rochette-Egly C. 2014. The biochemistry of retinoic acid receptors I: Structure, activation, and function at the molecular level. New York: Springer. $230 \mathrm{p}$.
2. Bookout AL, Jeong Y, Downes M, Yu R, Evans RM, Mangelsdorf DJ. 2006. Anatomical profiling of nuclear receptor expression reveals a hierarchical transcriptional network. Cell 126: 789799. doi: 10.1016/j.cell.2006.06.049

3. Dawson HD, Collins G, Pyle R, Key M, Taub DD. 2008. The retinoic acid receptor- $\alpha$ mediates human T-cell activation ant Th2 cytokine and chemokine production. BMC Immunol 9: 16. doi: 10.1186/1471-2172-9-16

4. Dawson MI, Xia Z. 2014. The retinoid $\mathrm{X}$ receptors and their ligands. Biochim Biophys Acta 1821: 21-56.

5. Dheda K, Huggett JF, Bustin SA, Johnson MA, Rook G, Zumla A. 2004. Validation of housekeeping genes for normalizing RNA expression in real-time PCR. BioTechniques 37: 112-114. doi: 10.2144/04371RR03

6. Gronemeyer H, Gustafsson J, Laudet V. 2004. Principles for modulation of the nuclear receptor superfamily. Nat Rev Drug Discov 3: 950-964. doi: 10.1038/ $\operatorname{nrd} 1551$

7. Hermoza E, Manchego A, Castro G, Pezo D, Sandoval N. 2018. Efecto del ácido retinoico sobre la expresión del receptor CCR 9 y la integrina alfa 4 beta 7 en leucocitos sanguíneos de alpacas (Vicugna pacos). Rev Inv Vet Perú 29: 349-361. doi: 10.15381/rivep.v29i1.14159

8. Holmgre J, Czerkinsky C .2005. Mucosal immunity and vaccines. Nature Medicine 11:45-53.

9. Iwata M, Yokota A. 2011. Retinoic acid production by intestinal dendritic cells. Vitam Horm. 86: 127-52. doi: 10.1016/ B978-0-12-386960-9.00006-X

10. Keightley MC. 1998. Steroid receptor isoforms: exception or rule? Mol Cell Endocrinol 137: 1-5. doi: 10.1016/s03037207(97)00236-0

11. Kim CH. 2008. Roles of retinoic acid in induction of immunity and immune tolerance. Endocr Metab Immune Disord Drug Targets 8: 289-294. doi: 10.2174/ 187153008786848312 
12. Lane MA, Bailey SJ. 2005. Role of retinoid signaling in the adult brain. Prog Neurobiol 75: 275-293. doi: 10.1016/ j.pneurobio.2005.03.002

13. Lefebvre P, Benomar Y, Staels B. 2010. Retinoid $X$ receptors: common heterodimerization partners with distinct functions. Trends Endocrinol Metab 21: :676-683. doi: 10.1016/j.tem.2010.06.009

14. Liu Q, Linney E. 1993. The mouse retinoid-X receptor-gamma gene: genomic organization and evidence for functional isoforms. Mol Endocrinol 7: 651-658. doi: 10.1210/mend.7.5.8391126

15. Mangelsdorf DJ, Umesono K, Kilewer $S A$, Borgmeyer $U$, Ong ES, Evans RM. 1991. A direct repeat in the cellular retinol-binding protein type II gene confers differential regulation by RXR and RAR. Cell 66: 555-561. doi: 10.1016/ 0092-8674(81)90018-0

16. Mangelsdorf DJ, Borgmeyer $U$, heyman RA, Zhou J, Ong ES, Oro A, Kakizuka A, et al. 1992. Characterization of three RXR genes that mediate the action of 9-cis retinoic acid. Genes Dev 6: 329-344. doi: 10.1101/gad.6.3.329

17. McGhee JR, Fujihashi K. 2012. Inside the mucosal immune system. PLos Biol 10(9): e1001397. doi: 10.1371/journal.pbio. 1001397

18. Mora JR, von Andrian UH. 2009. Role of retinoic acid in the imprinting of guthoming IgA-secreting cells. Semin Immunol 21: 28-35. doi: 10.1016/ j.smim.2008.08.002

19. Nagataavb T, Kannob Y, Ozatob K, Taketo M. 1994. The mouse Rxrb gene encoding RXRP: genomic organization and two mRNA isoforms generated by alternative splicing of transcripts initiated from CpG island promoters. Gene 142: 183189. doi: 10.1016/0378-1119(94)-90259-3
20. Nguyen V, Su C, Muyldermans S, Van der Loo W. 2002. Heavy-chain antibodies in Camelidae; a case of evolutionary innovation. Immunogenetics 54: 39-47. doi: 10.1007/s00251-002-0433-0

21. Niederreither K, Dollé P. 2008. Retinoic acid in development: towards an integrated view. Nat Rev Genet 9: 541 553. doi: $10.1038 / \mathrm{nrg} 2340$

22. Sonoda J, Pei L, Evans RM. 2008. Nuclear receptors: decoding metabolic disease. FEBS Lett 582: 2-9. doi: 10.1016/ j.febslet.2007.11.016

23. Stanley H, Kadwell M, Wheeler J. 1994. Molecular evolution of the family Camelidae: a mitochondrial DNA study. Proc Biol Sci 256: 1-6. doi: 10.1098/ rspb.1994.0041

24. Sun CM, Hall JA, Blank RB, Bouladoux N, Oukka M, Mora JR, Belkaid Y. 2007. Small intestine lamina propia of dendritic cells promote a new generation of Foxp3+T reg cells via retonoic acid. J Exp Med 204: 1775-1785. doi: 10.1084/jem.20070602

25. Takeuchi H, Yokota A, Ohoka Y, Kagechika H, Kato C, Song SY, Iwata M. 2010. Efficient induction of CCR9 on $\mathrm{T}$ cells requires coactivation of retinoic acid receptors and retinoid $\mathrm{X}$ receptors (RXRs): exaggerated $\mathrm{T}$ cell homing to the intestine by RXR activation with organotins. J Immunol 185: 52895299. doi: 10.4049/jimmunol.1000101

26. VanGundy ZC, Guerau-de-Arellano M, BakerJD, Strange HR, OlivoMarston S, Muth DC, Papenfuss TL. 2014. Continuous retinoic acid induces the differentiation of mature regulatory monocytes but fails to induce regulatory dendritic cells. BMC Immunol 15(8). doi: 10.1186/1471-2172-15-8 
27. Wang C, Kang SG, HogenEsch H, Love PE, Kim CH. 2010. Retinoic acid determines the precise tissue tropism of inflammatory Th 17 cells in the intestine. J Immunol 184: 5519-5526. doi: 10.4049/ jimmunol.0903942

28. Wheeler J.1995. Evolution and present situation of the South American Camelidae. Biol J Linn Soc Lond 54:
271-295. doi: 10.1016/0024-4066(95)90021-7

29. Wu C, Orozco C, Boyer J, Leglise M, Goodale J, Btalov S, Hodge CL, Haase J, Janes J, Huss J, Su A. 2009. BioGPS: an extensible and customizable portal for querying and organizing gene annotation resources. Genome Biol 10: R130. doi: 10.1186/gb-2009-10-11-r130 